\title{
Review Analysis of Light Vehicle Propeller Shaft
}

\author{
Shehnaj S. Mahboob ${ }^{1}$, Sunil Pagare ${ }^{2}$ Ankush K. Biradar ${ }^{3}$ Aamir Khan \\ ${ }^{I}$ (Student, Mechanical Engg, B. R. Harne College of Engg and Technology /Mumbai University, India) \\ ${ }^{2}$ (Guide, Mechanical Engg, B. R. Harne College of Engg and Technology /Mumbai University, India) \\ ${ }^{3}$ (HOD, Mechanical Engg, B. R. Harne College of Engg and Technology/Mumbai University, India)
}

\begin{abstract}
In recent times, with great focus on the economical saving uses of materials, the increased on the economical saving use of materials, the increased understanding of the machine method and nature of fatigue failure, and improvements in the mechanical design and analysis procedures, the popular thing/general way things are going towards conservatives has been reversed. Ordinary steel propeller-shafts are usually manufactured in two or more pieces to increase the basic bending natural frequency because the bending natural frequency of a shaft is (when one number goes one way, the other number goes the opposite way) to the square of beam length and (fair in amount, related to/properly sized, related to) the square root of clearly started/ particular modulus. Therefore the steel propeller shaft is made in two sections connected by a support structure, bearings and U-joints and because of this over all weight of composite materials. Composite (made up of different things) materials (Glass Epoxy) were used and designed and analyzed for their appropriateness in terms of torsional strength, bending natural frequency, torsional buckling and number of cycle by comparing.
\end{abstract}

Keywords: Drive Shaft, Composite Materials, Torsional Strength and Buckling strength.

\section{Introduction}

There are different types of shaft which includes: the transmission shaft, which transmits torquefrom on e location to another; the spindle; these are short shafts and the axles; which are non-rotating shafts. Shaft is one of the most widely used machine elements in different mechanical engineering applications, especially in power transmission.

They are found in applications such as the crankshaft, motivateler shaft, propeller shafts, camshafts etc. Shafts are usually tube like in shape and they provide supports for the other machine elements such as bearings, pullets, wheel and pinion like in shape and they provide supports for the other machine elements such as bearings, pulleys, wheel and pinion, etc, which are mounted on shafts. The design and producti on of shafts are deeply dug in/established in mechanical design and engineering ways of thinking and basic truths of thinking/basic truths/rules.

Analysis, (processes of figuring out the worth, amount, or quality of something) and engineering ways of thinking/basic truths are employed in the design to decide the stress, geometry and dimensions in range to the (thin slice that can be looked at) and the loading of theshaft. In recent times, with great focus on the money-saving use of materials, the increased understanding of the machine and nature of fatigue failure, and improvementsin the general mechanical design and analysis procedures, the popular thing/general way things are going towards conservatives has been reversed.

As a result of this, the cost of production has been reduced with safety and reliability stillgranted. Shaft $\mathrm{s}$ of different shapes and sizes can now be designed. Shafting or design of shafts, concerns basically with the str ong desire/formal decision about some things of the shaft dimensions to enable it survive the different loads on it and perform in an acceptable way under the different loading conditions. Specifically, it means the strong desire/formal decision about something of the correct shaft (distance or line from one edge of something, through its center, to the other edge) to survive or resist stresses acting on it in any form. The strength must prevent failure while the stiffness/lack of flexibility is needed to maintain good contact and to prevent life shortening of the different supporting elements such as the gears, pulleys etc in addition to the damages on the supporting elements, excess deflection will bring about whirling of shaft. To get a best design, it is necessary that the different loads and moments acting on the shaft be-taken into different. Shafts are used to transmit power from one member to another, and are subjected to bending and torsional load. To meet the needed things of strength and stiffness/lack of flexibility, a good chosen factor must be used to create a margin between the strength of the shaft and the stresses to be forced on it. The factor so chosen is the factor of safety. 


\section{Literature Review}

Charnont Moolwan, Samroeng Netpu, [1] has been investigation on failure analysis of a two high gearbox shaft of a gearbox in hot steel rolling mills, which fail prematurely after about 15,000 hours of service. They applied standard procedures for failure analysis for investigation. Basically there beach marks on fatigue fracture. Relatively small final fracture area of the fracture surface indicated that the shaft was under a low stress at the time of failure. They finally found that shaft has fatigue fracture and that premature failure failed due to high stress concentration at the corners of the wobbler of the shaft which led eventually to fatigue crack initiation, crack growth, and final fracture. So that they suggested to improved design and machining would be help for prolong service life of the shaft and component.

A.A. Adekunle et. al.[2] has investigation on shaft design and conservative in approach as relatively low working stresses. Their main objectives has prevents the shaft under various operating condition. Basically the maximum mechanism of failure mode of shaft was not well understood and because most of the applications in which shafts are employed are of great importance, which in some cases affects life negatively (i.e. involving loss of lives) and distortion of operations. Shaft design problem become more pronounced if the designer is interested in seeing the effects of the variation of one or more design parameter. They observed that on the basis of the coefficient static and dynamic safety, the value obtained for the co-efficient of static safety indicates that the material to be used for the design should be sufficiently plastic. Based on the co-efficient static and dynamic safety, the value obtained for the coefficient Of static safety indicates that the material to be used for the design should be highly alloy steel or a very Strong cast iron, and for that of co-efficient of safety indicates a lower accuracy of calculation which suggests a non-homogenous material is to be used with large diameters of shaft.

Y.A. Khalid et. al. [3] has been examination of weariness disappointment of under exploratory. They examination on two sorts of materials and discover twisting weakness investigation was done for half and half aluminum/Glass fiber composite drive shafts. Glass fiber with a lattice of epoxy gum and hardener were utilized to build the outside composite layers required. Four cases were considered utilizing aluminum tube injured by different layers of composite materials and different stacking succession or fiber introduction points. The disappointment mode for all the cross breed shafts was identified. The plainly visible level tests show that the splits starting in the zones free of fibers or in the external skin of sap and increment with expanding number of cycles until the disappointment of example. It has been found that there is no fiber breakage from the turning bowing exhaustion test. They have additionally found that expanding the quantity of layers would upgrade the exhaustion quality of aluminum tube up to $40 \%$, for [ \pm 45$]$. Some conclusion was found that:

1. Increasing the number of composite layers would increase the fatigue strength for a hybrid aluminum/ composite drive shaft;

2. There is no fiber breakage observed from the rotating fatigue tests.

3. Changing the stacking sequence of composite laminate may enhance the fatigue strength.

4. Aluminum shafts with laminates of a stacking sequence [+/45/_45] have the highest fatigue strength, up to $40 \%$ when compared to others.

Sh. Zangeneh et. al. [4] has study on failure analysis of a bad behavior-related shaft in a large vessel. Their analysis focused on break/crack surface examination and • finite element method (FEM) test run (that appears or feels close to the real thing) using Abaqus software for stress analysis. The results show that the steel shaft failed due to not enough fillet radius size. It was worked on the failure of shaft had due to torsional-bending tiredness during operation.

They found that torque applied to the shaft during mixing operation atconstant speed of $70 \mathrm{rpm}$ was ab out $372 \mathrm{Nm}$. stress raised up to $101 \mathrm{MPawithin}$ shaft,ange connection. This value in the shaft with a singlemachi ning groove with depth of $0.2 \mathrm{~mm}$ increases as much as 50\%. Also, static analysis showed that static analysis showed that stress rose at $\ddot{\imath} \neg$, ange/shaft connection up to $6 \mathrm{MPa}$ in steady state operation. On the basis of all the above stated, it can bedecided that not enough radius size and more importantly machining groves on the shaft surface was the main cause of the shaft failure.

R. Srinivasa Moorthy et. al. [5] has been investigation of improved failure and (slow chemical breakdown of something/rust, etc.) resistances, high clearly stated/particular strength and clearly particular modules and reduction in energy needed things because of reduction in weight in different material drive shaft. Carbon/Epoxy and Kevlar/Epoxy things (made up of different things) were designed and analysedfor their appropriateness in terms of torsional strength, bending naturalfrequency and torsional buc kling by comparing them with the ordinary steel Propeller-shaft under the same grounds of design restrictions and best-suited was recommended.

C.Elanchezhian et. al. [6] has investigation on traditional drive shafts made of SM45C Steel and compared with the Kevlar composite shaft. The Strength and Efficiency of the composite drive shaft is also tested. They has been first idealized as a hollow cylindrical shaft which is fixed at one end and on other end, to which a torque of $151 \mathrm{Nm}$. 


\section{Problem Definition}

Stainless steel was mainly used because of its high strength. But this stainlesssteel shaft has less clearly started particular strength and less clearly modules. Stainless steel has less damping ability (to hold or do something).Because of its higher density of molecules ofstainless steel, its weight is very high. Because of incre ase in weight fuelconsumption will in increase, the effect of (slow or no movement/the force of something moving) will be more. Because of increase in weight of thepropeller shaft we are replacing the stainless steel wit $\mathrm{h}$ the made up of different things materials, which are very less weight when compared to that of steel. The cost of made up of different things materials is lesswhen compared to that of stainless steel.

\section{Design Specification}

While designing a composite Propeller-shaft, the important aspects which are needed to be considered based on the and available standards of automotive Propeller-shaft are as follows. Here, the composite Propeller-shaft is designed for the specific application of passenger cars. The selected model of the passenger car is Maruti Suzuki Omni vehicle.

1. The Length of the Propeller-shaft is $0.562 \mathrm{~m}$.

2. The outer diameter of the Propeller-shaft of the vehicle is $52 \mathrm{~mm}$.

3. The shaft needs to withstand the Torsional buckling $(\mathrm{Tb})$ such that $\mathrm{Tb}>\mathrm{T}$.

4. The minimum bending natural frequency of the Propeller-shaft is $80 \mathrm{~Hz}$.

5. The maximum torque transmission capacity of the Propeller-shaft in passenger cars is $59 \mathrm{Nm}$.

Table 1 Mechanical Properties of Materials used for propeller shaft

\begin{tabular}{|l|l|c|c|}
\hline Mechanical Properties & Units & Steel (SM45C) & Glass Epoxy \\
\hline Young's Modulus $(\mathrm{E})$ & $\mathrm{GPa}$ & 207.0 & 43.3 \\
\hline Shear Modulus $(\mathrm{G})$ & $\mathrm{GPa}$ & 80.0 & 3.5 \\
\hline Poisson's Ratio $(\mathrm{v})$ & & 0.3 & 0.3 \\
\hline Density $(\rho)$ & $\mathrm{Kg} / \mathrm{m}^{3}$ & 7600 & 2100 \\
\hline Shear Stress $(\tau)$ & $\mathrm{MPa}$ & 29.419 & 65 \\
\hline
\end{tabular}

\section{Design Consideration of Propeller Shaft}

\section{A. Shaft subjected to torsional moment or torsion only}

The shaft is always subjected to torsion as it rotates. It is the case which is seen in almost every application. The torsional moment is always present in shaft due to its connections with gearbox or any other devices which produces torques. So, in this case the torsional shear stress is generated and it is calculated by,

$T=\frac{\pi}{16} \times \tau \times D^{3}$

Where, $\mathrm{T}=$ Torque transmitted

$\tau=$ Shear stress

$\mathrm{D}=$ Diameter of shaft

B. Shaft subjected to bending moment only,

First in this case from given load the bending moment is calculated at desired point of interest and on the basis of that bending moment the bending stress is to be found out and it is given by,

$\sigma_{b}=\frac{32 M}{\pi D^{3}}$

Where, $\mathrm{M}=$ Bending moment

$\sigma c=$ Bending stress

$\mathrm{D}=$ Diameter of shaft

\section{Shaft subjected to axial load only}

When the shaft is subjected to axial load only, it will be either tensile or compressive. So, the axial stress is given by,

$\sigma_{b}=\frac{4 F}{\pi D^{2}}$

Where, $\mathrm{F}=$ Axial force

$\sigma b=$ Axial stress

$\mathrm{D}=$ Diameter of shaft

D. Shaft subjected to combined bending and torsional load,

When there is no influence of axial load on shaft in that case the bending and torsion are only effective loads which act on the shaft. This case is often observed in various applications. In this case only bending and 
torsional loads are present so the combined load equation will contain the terms regarding to bending and torsional loads only, the equation of the combined stress or effective stress due to both loads is given by

$\sigma_{\text {eff }}=\frac{32}{\pi D^{3}} \sqrt{M^{2}+\frac{3}{4} T^{2}}$

Where, $\mathrm{M}=$ Bending moment

$\mathrm{T}=$ Torque transmitted

$\sigma$ eff $=$ Effective Von Mises stress

$\mathrm{D}=$ Diameter of shaft

This equation is based on Distortion energy or Von Mises failure theory and is used for ductile materials. The more simplified form of above equation is

$\sigma_{\text {eff }}=\frac{4}{\pi D^{3}} \sqrt{(8 M)^{2}+48 T^{2}}$

This equation is also presented in the form of principal stresses but some modification will take place as axial load is not present here so axial stress will be diminished. So, the conventional equation of principal stresses reduces to,

$\sigma_{1}, \sigma_{2}=\frac{\sigma_{b}}{2} \pm \sqrt{\left(\frac{\sigma_{b}}{2}\right)^{2}+\tau^{2}}$

Where, $\sigma 1=$ First principal stress

$\sigma 2=$ Second principal stress

Now, from above principal stresses the effective stress can be found by

$\sigma_{\text {eff }}=\sqrt{\sigma_{1}^{2}-\sigma_{1} \sigma_{2}+\sigma_{2}^{2}}$

E. Shaft subjected to combined axial, bending and torsional load,

The axial loads in shaft are seldom observed. Most of the times shaft is subjected to combination of bending and torsional load. The magnitude of axial load is quite less compared to bending and torsional loads so often it is neglected. But, here in this case the combined equation in the form of all three loading case is presented. So, the effective stress is given by

$\sigma_{\text {eff }}=\frac{32}{\pi D^{3}} \sqrt{\left[M+\frac{F D}{8}\right]^{2}+\frac{3}{4} T^{2}}$

The above equation is based on Von Mises theory of failure and it is used for ductile materials. The more simplified mathematical form of above equation is,

$\sigma_{\text {eff }}=\frac{4}{\pi D^{3}} \sqrt{[8 M+F D]^{2}+48 T^{2}}$

The equation for combined loading is also represented in the form of Principle stresses. The equations of principal stresses can be derived from Mohr's circle. So, the equations of principal stresses are,

$\sigma_{1}, \sigma_{2}=\left(\frac{\sigma_{a}-\sigma_{b}}{2}\right) \pm \sqrt{\left(\frac{\sigma_{a}-\sigma_{b}}{2}\right)+\tau^{2}}$

Now after finding these principal stresses the effective Von Mises stress can be found by above equation, So, by using any of the above equations the effective stress can be found out which must be less than yield stress to avoid failure. The reason behind using Von Mises failure theory is, as it is best suitable for ductile materials and also its yield envelope covers whole yield envelope of maximum shear stress theory which is also for ductile materials.

\section{Conclusion}

The substitution/replacement of traditional drive shaft brings about decrease in weight of vehicle. The limited component investigation programming is utilized by the numerous analysts for this work to anticipate the distortion of shaft. Essentially the diversions of steel, Glass Epoxy/HS Carbon and HM Carbon/Epoxy shafts were utilized for propeller-shaft. Characteristic recurrence utilizing Bernoulli - Euler and Timoshenko pillar hypotheses was looked at. The recurrence computed by Bernoulli - Euler hypothesis is high since it dismisses the impact of revolving inactivity and transverse shear. Henceforth the single piece High Strength Carbon/Epoxy composite drive shaft has been proposed to configuration to supplant the two piece regular steel drive shaft of a vehicle. The FEA examination was extremely useful for approval of scientific counts of his work. The consequences of the work are urging and recommending to substitution of ordinary propeller shaft by composite has an additional preferred standpoint. 


\section{References}

[1] Charnont Moolwan, Samroeng Netpu "Failure Analysis of a Two High Gearbox Shaft" Social and Behavioral Sciences Symposium, 1877-0428 International Science, Social Science, Engineering and Energy Conference 2012 (I-SEEC 2012), P r o c e d i a - Social and B ehavioral Sciences 88 (2013) $154-163$.

[2] A.A. Adekunle, S. B. Adejuyigbe, O.T. Arulogun "Development of CAD Software for Shaft under various Loading Conditions" Procedia Engineering 38 ( 2012 ) 1962 - 1983, International Conference on Modeling, Optimization and Computing,, 1877-7058

[3] Y.A. Khalid, S.A. Mutasher, B.B. Sahari, A.M.S. Hamouda "Bending fatigue behavior of hybrid aluminum/composite drive shafts" Materials and Design 2007, 329-334, 2005

[4] Sh. Zangeneh, M. Ketabchi, A. Kalaki "Fracture failure analysis of AISI 304L stainless steel shaft" Engineering Failure Analysis 36 (2014) 155-165

[5] R. Srinivasa Moorthy, Yonas Mitiku \& K. Sridhar "Design of Automobile Driveshaft using Carbon/Epoxy and Kevlar/Epoxy Composites" American Journal of Engineering Research (AJER) e-ISSN : 2320-0847 p-ISSN : 2320-0936 Volume-02, Issue-10, pp-173-179 www.ajer.org

[6] C.Elanchezhian, B.Vijaya Ramnath, K.N.Sripada Raghavendra, Mithun Muralidharan,G.Rekha "Design and Comparison of the Strength and Efficiency of Drive Shaft made of Steel and Composite Materials " ScienceDirect, Materials Today: PMME 2016. Selection and Peer-review under responsibility of International Conference on Processing of Materials, Minerals and Energy (July 29 th -30 th) 2016 , 